\title{
The Professional Biologist and Advocacy: What Role Do We Play?
}

\section{STEPHEN DESTEFANO}

\author{
USGS, Massachusetts Cooperative Fish and Wildlife Research Unit \\ University of Massachusetts \\ Amherst, Massachusetts, USA
}

\section{ROBERT J. STEIDL}

School of Renewable Natural Resources

University of Arizona

Tucson, Arizona, USA

\begin{abstract}
Professional biologists assume a variety of roles during their careers. The potential role of advocate has come under increased debate and scrutiny by the public, resource users, legislators, and professional biologists themselves. We believe that biologists should offer their opinions on resource issues if those opinions are based on data, experience, and insight. As much as possible, professionals should resist involving personal philosophies, agendas, and emotions in favor of the most objective stance possible, realizing that there will be instances when they will be asked for their opinion when sufficient data are lacking, but biologists should not always defer to others to make interpretations and construe implications of data without their participation. This approach is best described as professional or expert opinion. Professionals should guard their unique position of providing reliable information and expert opinions while striving for objectivity and impartiality: For many professionals, controversy and confrontation will remain an aspect of the job, but the approach of offering input based on science and experience would allow professional biologists to perform their duties and participate meaningfully in the conservation and managentent of natural resources.
\end{abstract}

Keywords Advocacy, conservation, natural resource issues

We thank the individuals and agencies who contributed information on advocacy, and W. W. Shaw and C. Yde of the University of Arizona for financial and logistic support. We also thank D. Minnis and R. Stout-McPeake for organizing the symposium on advocacy that prompted this paper, and for their comments as well as those of $K$. Koenen on the manuscript.

Address correspondence to Stephen DeStefano, U.S. Geological Survey, Massachusetts Cooperative Fish and Wildlife Research Unit, Holdsworth Natural Resources Center, University of Massachusetts, Amherst, MA 01003. E-mail: sdestef@forwild.umass.edu 


\section{Introduction}

Professional biologists find themselves assuming a variety of roles during the course of their careers: researcher, manager, educator, administrator, public relations specialist. The relative importance of these roles may vary among jobs, but they are not mutually exclusive and as a profession we share a common goal: increasing knowledge and improving management of natural resources. Increasingly, biologists question whether they should be advocates for natural resources and whether advocacy is compatible with other roles in the profession. Advocacy and its implications has thus become controversial and a much-debated topic in the wildlife and fisheries professions. This is particularly true with regard to research and science (Adams \& Hairston, 1996; Sweeney \& Stangel, 1995), but it is equally applicable to how professionals manage, educate, administer, and relate to the public.

In this paper, we explore advocacy as it relates to professional biologists, particularly research scientists but also managers and educators. We define advocacy in the realm of wildlife and fisheries science, discuss the role of scientists in providing reliable information, debate the pros and cons of "taking a stand," and present a case history and results of a questionnaire mailed to natural resource agencies that address the question of advocacy. Finally, we suggest that a forthright expression of professional opinion is an alternate route for biologists through the advocacy maze.

\section{Definitions and Values}

\section{A Definition of Advocacy}

Advocacy is defined as "to openly espouse or support a cause or position" (Webster, 1993). The implications of advocacy in today's society, however, are much more complex than this definition implies, and there are many consequences to consider, whether a professional chooses to advocate a position or not.

Advocacy involves issues such as freedom of speech, scientific credibility, and personal and professional integrity. Adding to the complexity is the underlying fact that science, as well as management, education, administration, and public relations, has components that are value-laden (O'Brien, 1993). Science may be defined as the objective pursuit of knowledge through structured means such as hypothesis testing, but it is not a purely objective undertaking by purely objective means (e.g., see Johnson, 1999). Decisions regarding what to study (and manage, teach, and promote) are interwoven with values (O'Brien, 1993). Therefore, no one is completely objective, but professional biologists should strive to be as completely objective as possible.

The term advocacy has also come to be associated with extremist viewpoints, partly fueled by radical reactions to resource issues reported in the news media. Thus, the public sees complex issues broken down to an oversimplified frame- 
work of "us versus them." During the heat of these confrontations, individuals who disagree often label their opponents "advocates." These attitudes have stifled many biologists from offering informed opinions on controversial issues, which is bad for the profession and the resource.

Advocacy can thus have many meanings depending on who uses the term and the situational circumstances of its use. Ignoring these complexities, we find it difficult to improve on Webster's (1993) definition. The conundrum comes with how to "openly espouse or support" and maintain professional credibility and integrity.

\section{Hierarchy of Values}

Humans place value on everything, and in one sense or another we advocate causes, ideas, and ideals every day. In a recent informal survey of the World Wide Web, we searched for the word "advocacy" and received 2,720,000 "hits." A cursory review of the first 100 sites revealed that people advocate for a wide variety of

TABLE 1 Compilation of the First 100 Web Sites Listed Under the Keyword "Advocacy" on the Internet World Wide Web

1. Law and legislation

2. Politics and government

3. Liberal ideologies

4. Conservative ideologies

5. Labor organizations

6. Public policy

7. Human rights

8. Disabilities/alter-abled access

9. Children's issues

10. Family issues

11. Senior citizens

12. Women's rights

13. Coalition for the preservation of fatherhood

14. Sexual harassment

15. Consumer rights and protection

16. Welfare rights

17. Adolescent pregnancy prevention

18. AIDS

19. Alzheimer's disease

20. General and family health

21. Mental health
22. Methadone-A legitimate treatment alternative

23. Personal credit and finances

24. International aid (e.g., Oxfarm)

25. Ending world hunger

26. Peace Corps

27. Censorship and regulation

28. Computer advocacy

29. Cyberspace advocacy

30. Telecommunications, advertising, and marketing

31. People for affordable telephone service

32. The Arts

33. Bicycling (many groups)

34. Education

35. Science (National Science Foundation)

36. Advanced technology

37. Voting

38. Victims of violent crimes 
topics (Table 1). Natural resource topics certainly did not dominate the first 100 sites, but many nongovernmental organizations (NGOs) and private groups advocating wildlife and natural resource conservation were well represented.

Values can also be prioritized. For example, freedom of speech is arguably one of the most basic values in the United States. When debating whether or not to advocate, our rights as citizens take precedence over our status as employees. Some administrators may cite agency policies to the contrary, but the fact is that free speech is upheld in court on virtually every occasion, including those cases when biologists speak in opposition to their agency (e.g., Public Employees for Environmental Responsibility, 2000).

We are not suggesting that biologists openly challenge their supervisors in adversarial situations. In fact, being a "team player" and presenting a unified front on controversial issues is more important now than ever. However, the right to free speech prevails for all citizens, including government employees. Along with this freedom, of course, comes tremendous and sometimes overlooked responsibility, which includes speaking honestly, not slanting interpretations to support preconceived views, and considering and respecting the opinions of others (supervisors included). The debate over advocacy is not if professional biologists can speak their minds on controversial issues-the First Amendment of the Constitution guarantees that we can-but when we should, and if so, how we can while maintaining credibility and integrity.

\section{Reliable Information}

Central to the wildlife and fisheries professions is providing colleagues and the public with reliable, unbiased information on ecology and management. Although the best approach may be debatable (e.g., Johnson, 1999; Romesburg, 1991), the accumulation, interpretation, dissemination, and implementation of reliable knowledge on natural resources is a primary goal for biologists. Interest in natural resources is widespread in the United States and many other countries, but relatively few individuals have the training or experience of professional biologists. If the reported information is tainted by subjectivity, biases, emotions, or an agenda, the professional and the profession will be compromised. This should be the central thought for any professional biologist considering where he or she stands on the issue of advocacy.

\section{A Survey of Natural Resource Agencies}

To understand how resource agencies have addressed the issue of advocacy, we mailed a brief questionnaire to state $(n=50)$ and federal $(n=7)$ agencies requesting information on policies and agency history regarding advocacy in agency operations. Almost three fourths ( $72 \% ; 37$ states and 4 federal agencies) responded 
TABLE 2 Responses of State $(n=37)$ and Federal $(n=4)$ Resource Management Agencies to Questions About Agency's Role in Advocacy ("Unknown" or Missing Responses Were Ignored).

\begin{tabular}{|c|c|c|c|}
\hline \multirow[b]{2}{*}{ Question } & \multicolumn{3}{|c|}{ \% Responses } \\
\hline & $n$ & Yes & No \\
\hline Does your agency have an official policy on advocacy? & 41 & 82.9 & 17.1 \\
\hline $\begin{array}{l}\text { Does your agency have suggested guidelines on } \\
\text { advocacy? }\end{array}$ & 36 & 66.7 & 33.3 \\
\hline $\begin{array}{l}\text { Does your agency have plans to develop an official } \\
\text { advocacy policy? }\end{array}$ & 25 & 11.1 & 58.3 \\
\hline $\begin{array}{l}\text { Has your agency received recommendations or directives } \\
\text { from official legislative or legal governing bodies? }\end{array}$ & 37 & 54.1 & 45.9 \\
\hline If so, has your agency instituted these directives? & 16 & 87.5 & 12.5 \\
\hline $\begin{array}{l}\text { Has your agency received recommendations from } \\
\text { outside groups (e.g., nongovernmental environmental } \\
\text { organizations)? }\end{array}$ & 32 & 43,8 & 56.2 \\
\hline If so, has your agency instituted these recommendations? & 15 & 53.3 & 46.7 \\
\hline $\begin{array}{l}\text { Has your agency been involved in an advocacy-related } \\
\text { issue? }\end{array}$ & 38 & 71,1 & 28.9 \\
\hline If so, would you consider the issue controversial? & 27 & 92.5 & 7.5 \\
\hline
\end{tabular}

after two mailings (Table 2). Most had either an official policy or suggested guidelines in place regarding advocacy. Only $11 \%$ of those without an existing policy or guidelines had plans to develop such policies or guidelines.

Several respondents stated that advocacy needed to be defined clearly. One respondent wrote:

"... taking political or associated actions to advance a cause, ideology, or philosophy . . . is quite different than actions to promote agency mandates, programs, policies, and recommendations."

Many agencies' policies or guidelines encouraged employees to represent the agency but leave personal feelings at home. Still other agencies reported that the term "advocate" had been in their mission statement before advocacy became a controversial topic. One respondent stated, "We believe that a part of our basic mission is to advocate for wildlife and wildlife habitat conservation, protection, and enhancement." This is further evidence that many professionals believe that it is their duty and responsibility to stand up for proper management, use, and protection of natural resources. Still, there is the question of how to do this and maintain credibility as scientists, managers, and educators. 


\section{Science-based Management Decisions: An Example}

Examples of controversial management decisions abound in natural resources. One example involves lynx (Lynx canadensis) populations, timber harvest, and fur trapping in northern Washington. The lynx's range in the continental United States has been reduced mainly to areas near the Canadian border. This limited range has been attributed to heavy trapping activity around the turn of the century and continued habitat loss (DeStefano, 1987). The populations that remain just south of the Canadian border are low density and thus subjected to the vagaries that often plague small populations.

Several contentious issues developed among groups interested in managing lynx populations in northern Washington: (1) the degree of timber harvest, if any, that should be allowed in lynx habitat; (2) re-opening a trapping season for lynx that had been closed for several years; and (3) whether the lynx should be listed as a threatened or endangered species under the Endangered Species Act (ESA). The question here is not specifically what to do about lynx management per se, but what could a biologist say about lynx management without being labeled an advocate by one side or the other? Perhaps nothing: No matter what a biologist said or did not say, some measure of advocacy could be construed by participants in the debate.

Where does this leave the biologist? The professional is left to offer an opinion based on data interpretation, experience, and insight. In the lynx example, allowing some timber harvest likely would benefit lynx by promoting early successional habitat for important prey species like snowshoe hares (Lepus americanus). However, large clearcuts could be harmful as would an increase in road access, which usually accompanies logging, because of the increased probability of illegal harvest and traffic fatalities. A continuation of the closed trapping season would reduce losses of established adult breeders, which are vital to small populations of long-lived animals. And finally, lynx should be listed under the ESA if the population truly is in danger of extinction, rather than being listed as a proxy to protect old-growth forest.

None of these statements constitutes "taking sides" but rather reflects an opinion based on accumulated knowledge, experience, and insight. These views have nothing to do with "pro" or "con" feelings about timber harvest, fur trapping, or the ESA, but instead are based on relevant studies in northern Washington and the scientific literature. Regardless, voicing such opinions is enough for some to label a biologist a "greenie," "biostitute," or "advocate," depending on the views of the accuser. So be it; the alternative is to stay silent, which does not help lynx, natural resources, society, or our profession.

Perhaps in this and many other cases, advocacy is no longer the correct term because of its etymological evolution into a word that implies controversy and confrontation. When a professionally trained biologist offers an informed view, we believe professional opinion is the correct label. Biologists should offer rea- 
soned and balanced viewpoints on topics for which they have knowledge and experience, resist the temptation to wade into emotional arguments, and continually strive to recognize the difference. Advancing ideologies is not the mark of a professional, but offering expert opinion is.

\section{Advice for Students and Early Career Professionals}

Before speaking out on controversial issues, biologists should consider, among other things (Table 3), the quality of the available scientific information, how well informed they are on the issue, and how they will be perceived. Some of these considerations are especially important to students and younger professionals. The strongest and most effective voices for sound management and conservation of natural resources are often those people who have first established careers and developed reputations as being credible and fair. Many groups openly advocate for wildlife and natural resources, but few are as concerned with providing unbiased and reliable information as professional biologists. The latter should be the hallmark of the biology profession, and one that we should consider well and guard jealously. In general, however, our responsibilities should not end with merely collecting data. We have a responsibility as professionals to evaluate and interpret that data, thus making it useful to land managers, politicians, decision makers, and the public. All the while, we should strive for objectivity, which means constant and open testing and questioning by colleagues, peers, and the public.

At what point in a career does a professional decide to play more of a vocal role? Theoretically, opinions can be voiced throughout a career if one has firsthand knowledge of the issue, can make data-based decisions, and speaks strictly

TABLE 3 Some Considerations for Professional Biologists When Facing Issues of Advocacy

- Maintain objectivity.

- Be uncompromising about data, especially your own.

- Remember the professional's unique position in providing reliable information.

- Do your homework; know the background, the literature, and opposing viewpoints.

- Listen to others on all sides of any issue.

- Have confidence in your training and abilities.

- Recognize your boundaries.

- Remain calm and focused, respectful and polite.

- Do not be afraid to participate.

- Maintain a focus on the resource. 
to the biology of the situation. Controversial issues are never quite that simple, however. Knowing when and how vigorously to speak ultimately will be a personal decision. Seeking appropriate role models will help; those individuals who have strong science and management backgrounds and even and fair-minded temperaments are good role models.

\section{Professionals Defining Their Role}

We do not expect this paper nor the special section of this journal to help the profession reach a clear consensus about the role of the biologist and advocacy, given the diversity of opinions and level of personal choice involved. Returning to Webster's (1993) dictionary, even its relatively simple definition contains ambiguity. We feel that to "support a position" is a more acceptable role for a professional biologist than to "espouse a cause." However, to shun controversy and professional responsibility for fear of being labeled an advocate is ineffective. Professionals should be involved in controversial issues and make valuable contributions to difficult decisions. Merely providing data for others to interpret and draw conclusions is unacceptable and dangerous. We would much prefer that important decisions on natural resource issues have the benefit of opinions expressed by experienced colleagues, rather than conclusions arrived at solely by lawyers, politicians, or even environmental groups. However, it is critical for professional biologists to pay strict heed to what they say, how they say it, and the quality of the information on which their opinion is based. A professional's most valuable contribution to society is in using their education and experience to illuminate important and even controversial issues in an objective and unemotional manner. The professional biologist should be known for "supporting a position" based on education, experience, and their life's work rather than "espousing a cause."

As the debate about advocacy proceeds, professionals need to ask themselves when it is appropriate to voice an opinion, when it is appropriate to refrain, and what are the implications of either action. We need to continue to examine our responsibilities as professionals to society and the resource, and to provide our professional opinion when the situation allows.

\section{References}

Adams, P. W., \& Hairston, A. B. (1996). Calling all experts: Using science to direct policy. Journal of Forestry, 94, 27-30.

DeStefano, S. (1987). The lynx. In R. L. Di Silvestro (Ed.), Audubon Wildlife Report 1987 (pp. 410-422). Orlando, FL: Academic Press.

Johnson, D. H. (1999). The insignificance of statistical significance testing. Journal of Wildlife Management, 63, 763-772.

O’Brien, M. H. (1993). Being a scientist means taking sides. Bioscience, 43, 706-708. 
Public Employees for Environmental Responsibility [PEER]. (2000). Newsletters from the World Wide Web: http://peer.org/action/.

Romesburg, H. C. (1991). On improving the natural resources and environmental sciences. Journal of Wildlife Management, 55, 744-756.

Sweeney, J. M., \& Stangel, P. W. (1995). Walking the line: Science versus advocacy. Transactions of the North American Wildlife and Natural Resources Conference, 60 , 1-5.

Webster, D. (1993). Webster's new encyclopedic dictionary. New York: Black Dog and Leventhal Publishers. 